\title{
Analysis of Local Moisture Increase of Timber Constructions on Ice Arena Roof
}

\author{
Antonin Zak ${ }^{1, a}$, Ondrej Sikula ${ }^{2, b}$ and Miroslav Trcala ${ }^{3, c}$ \\ ${ }^{1}$ Department of technical development and research, Dektrade a.s., Brno, Czech Republic \\ ${ }^{2}$ Institute of Building Services, Faculty of Civil Engineering, Brno University of Technology, Czech \\ Republic \\ ${ }^{3}$ Department of Wood Science, Faculty of Forestry and Wood Technology, Mendel University in \\ Brno, Czech Republic \\ aantonin.zak@dek-cz.com, bsikula.o@fce.vutbr.cz, 'MiroslavTrcala@seznam.cz
}

Keywords: roof, ice arena, ice rink, timber, wood, moisture, humidity, temperature, degradation, CFD.

\begin{abstract}
Timber is one of the most used materials for roofing of ice arena because of its very good mechanical properties and low weight. High relative humidity of internal air, low temperature and ice rink presence, which cause fall of surface temperatures of constructions under the dew point due to radiation, are risky factors not only from structural point of view, when load bearing capacity of construction in time is reduced, but also from the view point of bio corrosion. Specific hygrothermal microclimate, different from air parameters in the ice arena, is formatted close to the individual members of roof construction. Newly developed mathematical and physical model using CFD simulation is used for simulation of hygrothermal stress in chosen part of the ice arena roof construction, which substantially affects quality, utility properties and life time of timber roof components. Results are compared with experiments in specific ice rink.
\end{abstract}

\section{Introduction}

Timber is one of two most often used materials for the load-bearing structures of ice arena roofs. The reason is low weight, high strength and timber appearance, often sought-after by architects. Apart from indisputable advantages for its applications on load-bearing structures, timber has also its natural properties which cannot be omitted. These are, for example, a high absorption of water, liability to attack by wood-damaging pests, non-isotropic physical properties, etc. In relation to climatic conditions in interior, ice arenas are specific for their low temperature, high relative humidity of internal air and ice rink presence. The ice rink acts as a cold body which transfers a large amount of heat by radiation with the other constructions, mainly roof constructions. The radiation component of thermal energy, which is almost omitted in common constructions due to its small effect, is quite fundamental in ice arenas. The ice rink radiation causes cooling of the roof construction surfaces by up to units of Kelvin; more details see publications [1] and [2]. This drop in the surface temperature of constructions is usually most noticeable above the ice rink centre at the roof surfaces that are turned straight to the ice rink. In highly emissive materials, the surface temperature can drop below the dew point temperature of the air even at internal air humidity around $75 \%$. Not only the long-term action of liquid condensed water, but also the increased air humidity in the surrounding of cooled timber constructions are the cause of a decrease in biological resistance and a deterioration of the mechanical properties of wood mass.

To assess long-term risks of wood degradation and changes in mechanical properties due to an increased moisture, it was necessary to create a simplified 2D model for solving time-steady heat and humidity transfer in timber constructions taking the ice rink radiation into account. The model was validated by experimental measurement.

The analysis was carried out on the timber construction of the ice arena in Vrchlabí. The loadbearing part of the roof is made up of timber framed girders on which, at an axial distance of $3 \mathrm{~m}$, there are timber purlins and formwork made of OSB $22 \mathrm{~mm}$ in thickness. The roof composition is 
designed as a single-deck roof with the conventional order of layers with thermal insulation of expanded polystyrene $50 \mathrm{~mm}$ in thickness. The arena is ventilated by air circulation distribution ducts located in the roof's framed construction above the ice rink edge.

\section{Computer simulation methods}

The available measured data did not provide sufficient information for the required risk analysis of wood degradation, therefore, to obtain the necessary information, numerical CFD simulations in the Fluent program and our own numerical model were used. To ensure compatibility of the data used, the Fluent program results were validated first by the values measured in the ice arena in Vrchlabí.

The Fluent program cannot solve the flow of liquid with admixture directly and, at the same time, solve diffusion of this admixture in solid substances. So it was necessary to tie up the Fluent results with the moisture diffusion in solid substances. This was achieved by creating our own 2D numerical model based on differential equations for heat and moisture transfer (1) in solid substances with the orthotripic character of material properties.

This model is able to calculate equilibrium moisture content of timber for particular conditions on its surface and moisture distribution in the whole cross-section for timber with moisture below the hygroscopicity limit (up to $30 \%$ ).

With regard to the experimentally found small temperature variation in wood in time and the small effect of short-term temperature and moisture variations in wood on stability and resistance against biological corrosion, the solution of time steady processes was chosen. The thermaltechnical properties of timber elements were considered for average values independent of temperature and moisture changes. The two-dimensional transfer of heat and moisture is described as follows:

$$
\frac{\partial}{\partial x}\left(\lambda_{x} \frac{\partial T}{\partial x}\right)+\frac{\partial}{\partial y}\left(\lambda_{y} \frac{\partial T}{\partial y}\right)=0, \frac{\partial}{\partial x}\left(D_{x} \frac{\partial M}{\partial x}\right)+\frac{\partial}{\partial y}\left(D_{y} \frac{\partial M}{\partial y}\right)=0
$$

where $D_{x}$ and $D_{y}$ are the moisture diffusion coefficients of wood $\left[\mathrm{m}^{2} \mathrm{~s}^{-1}\right], \lambda_{x}$ and $\lambda_{y}$ are the thermal conductivity coefficients of wood $\left[\mathrm{Wm}^{-1} \mathrm{~K}^{-1}\right], M$ is the moisture content [\%], $T$ is the temperature $[\mathrm{K}]$.

In relation to negative radiation, the most loaded constructions are usually the bottom surfaces of the bottom strips of framed girders or plain girders located near the ice rink centre, see the thermographic image in Fig. 1b). To find out the effect of radiation on various elements, also a heatmoisture analysis was carried out for the top strip of the girder located 4 metres higher.

Simulations were carried out on two simplified geometries of the arena, specifically a 3D model of the arena quarter, see Fig. 1c) and a 3D model with a periodically repeating segment of the arena, see Fig. 1d).

The very good accordance of the experiment results with the CFD simulation, in the order of inaccuracy of up to approx. 5\%, allowed us, for the final heat-moisture assessment of wooden elements, to use the experiment values and to add the missing surface temperatures on both strips of the girder from the simulations.

Basic equations for determining EMC (equilibrium moisture content) used for simulation are provided, for example, in publication [3]. 


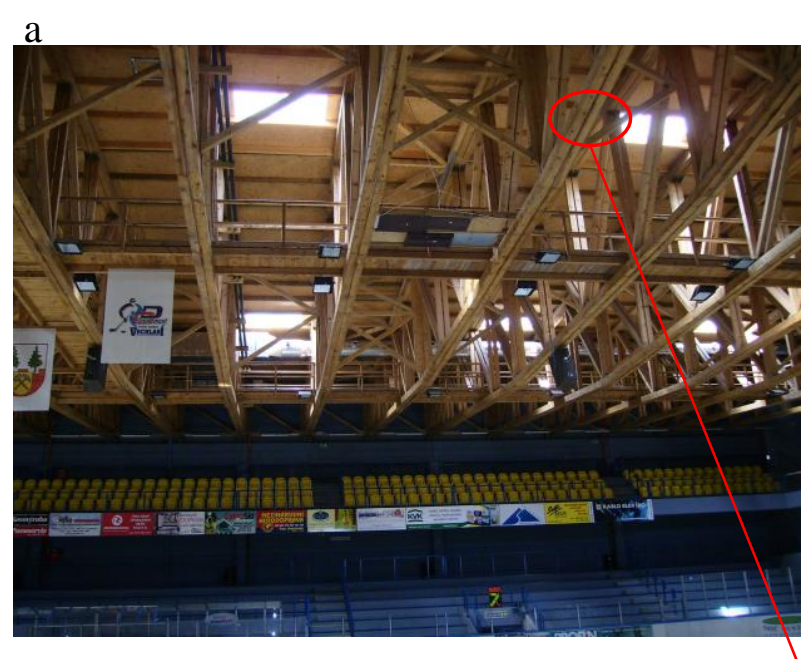

b

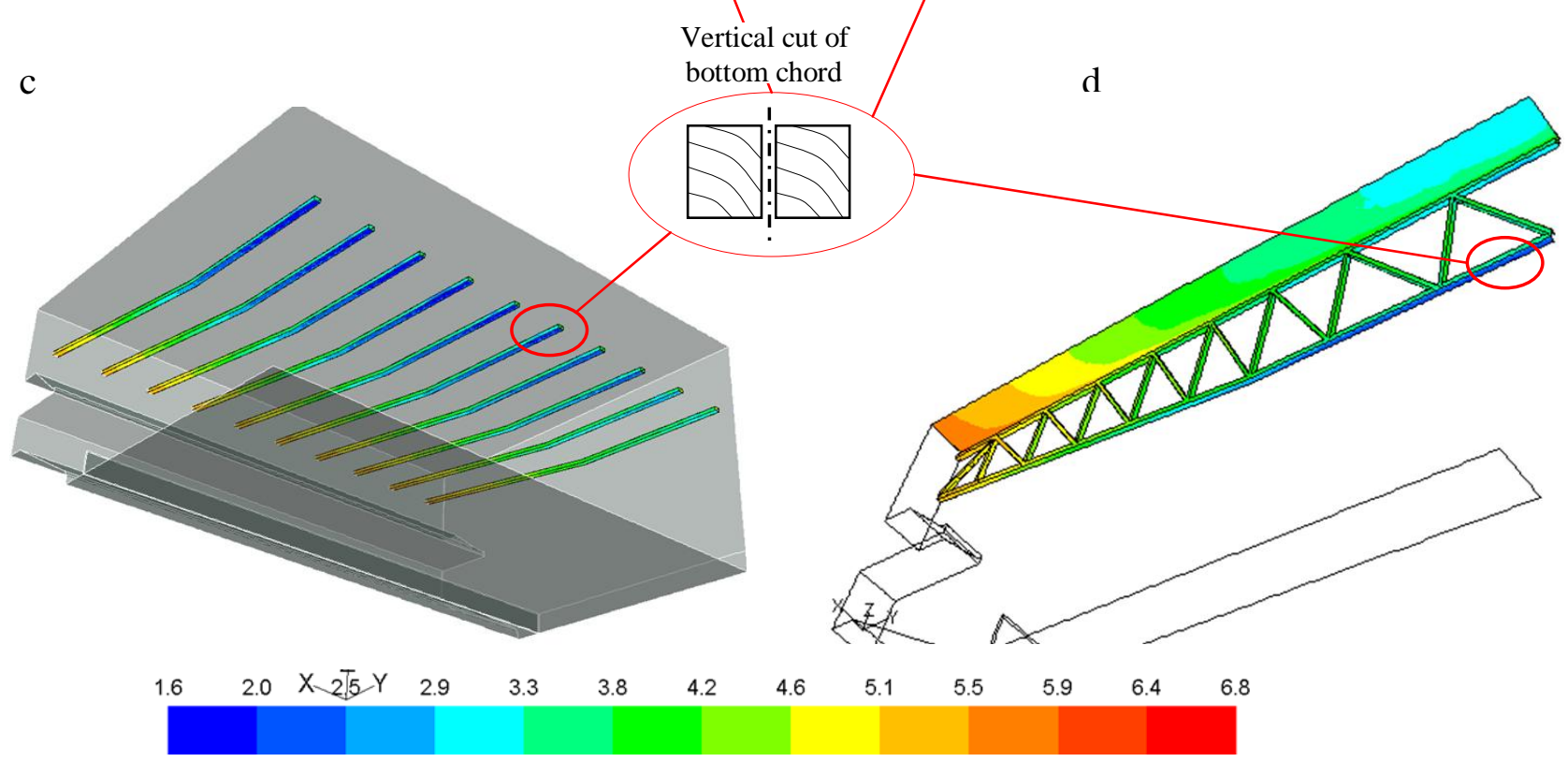

Fig. 1 a) View of the roof construction, surface temperatures $\left[{ }^{\circ} \mathrm{C}\right]$ determined b) experimentally c) by simulation on the arena quarter d) by simulation on the arena segment
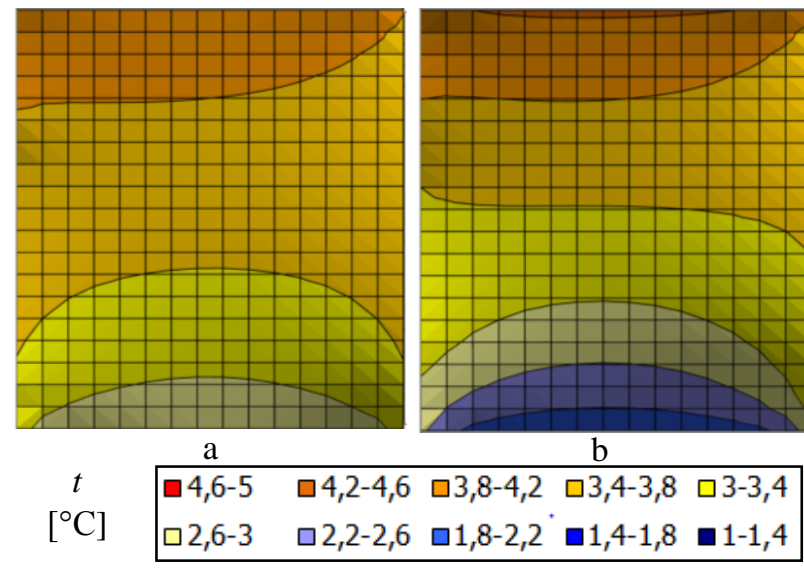

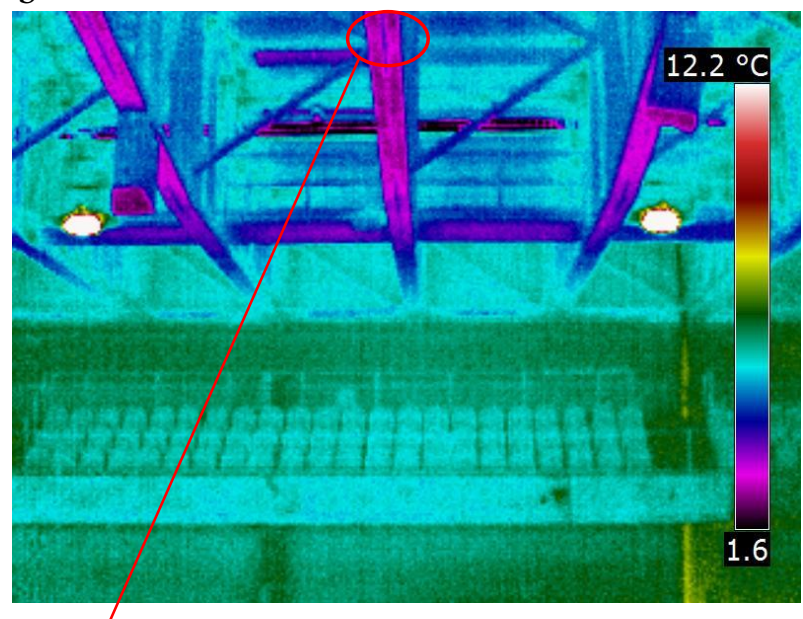

d$$
\text { . }
$$ 


\section{Discussion of the results}

The results obtained clearly show to a significant moisture increase in the assessed girder by effect of its having been radiated by the ice rink. The difference of the calculated distribution of wood moisture in its cross-section and equilibrium moisture at the temperature and humidity of the ambient air is more than 3\% in this case. In publication [4] it is stated that for wood with a moisture content between $8 \%$ and $20 \%$ an approximately linear dependence between moisture and mechanical properties can be considered. At a one-percent change in wood moisture content, tensile strength in the direction of fibres changes by approximately $2.5 \%$ and pressure strength in the direction of fibres by approximately $6 \%$. Therefore pressed elements are more risky in relation to the effect of moisture.

The limit of $20 \%$ of the relative moisture of wood for constructions made of natural timber is very important. According to [5], constructions located in an environment with a relative humidity of up to $20 \%$ are classified in class 2 operation. Constructions with humidity above $20 \%$ fall to class 3. The difference in the reduced strength of wood between classes 2 and 3 is approx. $15 \%$ to $20 \%$.

However, when designing timber constructions, the 2nd limit state, i.e. deformation, is usually decisive. Classification in class 2 or 3 is of fundamental importance for the calculation of deformation, mainly for constant load. According to [5], constructions classified in class 3 show approx. $70 \%$ higher deformation for constant load.

It is apparent from Fig. 2 that only the bottom third of cross-section of the bottom strip of the girder is in the higher wood moisture (above approx. 18\%). It can be also stated that individual elements of the framed construction are loaded by radiation differently, so also a different moisture load can be expected. The top strip of the girder shows approx. 3\% to $4 \%$ lower moisture and it is safely below the limit of $20 \%$. According to Fig. 1, the surface temperatures of girder elements located outside the ice rink area are significantly higher, so a significantly lower moisture can be expected.

\section{Conclusion}

The aim of the article is to suggest possible difficulties in the selection of the moisture classes (environment class) of wood when designing and assessing the timber load-bearing constructions of ice arena roofs. The above-mentioned heat-moisture analysis may provide valuable information for designing an economical, but still sufficiently safe construction. It must be kept in mind that the values provided in the article were obtained for the ice arena with internal air treatment. In a naturally ventilated arena the data would be significantly different. The problems of biological corrosion were described in more details in the article [2].

\section{Acknowledgements}

The contribution was prepared with support of the Specific Research 2012 at the Brno University of Technology, Grant FAST-J-12-1781 and with non-financial support of the town of Vrchlabí as the ice arena operator.

\section{References}

[1] A. Zak, Analysis of ice rink roofs cladding solution, Dissertation thesis, Brno, 2011.

[2] A. Zak, O. Sikula, Ice arena timber roof construction from the point of view of thermal technology, Stavebnictví (annex). 33 (2012) 28-32.

[3] M. Trcala. A 3D transient nonlinear modelling of coupled heat, mass and deformation fields in anisotropic material, International Journal of Heat and Mass Transfer, 55 (2012) 17-18.

[4] B. Kozelouh, Timber structure according to the eurocode 5 - STEP 1, first ed., KODR, Zlín, 1998.

[5] Eurocode 5: Design of timber structures - Part 1-1: General - Common rules and rules for buildings (ČSN EN 1995-1-1), 114 (2006). 